\title{
Allogeneic transplantation of mobilized dental pulp stem cells with the mismatched dog leukocyte antigen type is safe and efficacious for total pulp regeneration
}

Koichiro lohara', Shinji Utsunomiya², Sakae Kohara ${ }^{3}$ and Misako Nakashima ${ }^{{ }^{*}}$

\begin{abstract}
Background: We recently demonstrated that autologous transplantation of mobilized dental pulp stem cells (MDPSCs) was a safe and efficacious potential therapy for total pulp regeneration in a clinical study. The autologous MDPSCs, however, have some limitations to overcome, such as limited availability of discarded teeth from older patients. In the present study, we investigated whether MDPSCs can be used for allogeneic applications to expand their therapeutic use.

Methods: Analysis of dog leukocyte antigen (DLA) was performed using polymerase chain reaction from blood. Canine allogeneic MDPSCs with the matched and mismatched DLA were transplanted with granulocyte-colony stimulating factor in collagen into pulpectomized teeth respectively ( $n=7$, each). Results were evaluated by hematoxylin and eosin staining, Masson trichrome staining, PGP9.5 immunostaining, and BS-1 lectin immunostaining performed 12 weeks after transplantation. The MDPSCs of the same DLA used in the first transplantation were further transplanted into another pulpectomized tooth and evaluated 12 weeks after transplantation.
\end{abstract}

Results: There was no evidence of toxicity or adverse events of the allogeneic transplantation of the MDPSCs with the mismatched DLA. No adverse event of dual transplantation of the MDPSCs with the matched and mismatched DLA was observed. Regenerated pulp tissues including neovascularization and neuronal extension were quantitatively and qualitatively similar at 12 weeks in both matched and mismatched DLA transplants. Regenerated pulp tissue was similarly observed in the dual transplantation as in the single transplantation of MDPSCs both with the matched and mismatched DLA.

Conclusions: Dual allogeneic transplantation of MDPSCs with the mismatched DLA is a safe and efficacious method for total pulp regeneration.

Keywords: Allogeneic cell transplantation, Pulp regeneration, Mobilized dental pulp stem cells, Granulocyte-colony stimulating factor, Pulpectomy, Dog leukocyte antigen, Dual transplantation

\footnotetext{
*Correspondence: misako@ncgg.go.jp

${ }^{1}$ Department of Stem Cell Biology and Regenerative Medicine, National

Center for Geriatrics and Gerontology, Research Institute, 7-430 Morioka, Obu,

Aichi 474-8511, Japan

Full list of author information is available at the end of the article
} 


\section{Background}

Pulp/dentin complex in teeth has a critical function in the maintenance of tooth homeostasis, and viable pulp is essential for the longevity of the tooth [1]. The ultimate goal for regenerative endodontics is to replace or restore the impaired or damaged tissues with viable pulp tissue in the case of pulpitis or apical periodontitis, leading to the reestablishment of the physiologic, structural, and mechanical integrity of the native dentin/pulp complex, including function of pulp immunity, dentin formation, pulp innervation, and vascular perfusion [1-4]. Stem cell therapy has been suggested as an effective regenerative technique for pulpitis and apical periodontitis. Autologous transplantation of dental pulp stem cell (DPSC) subsets, dental pulp-derived $\mathrm{CD} 31^{-}$side population (SP) cells, or $\mathrm{CD} 105^{+}$cells with SDF1 in orthotopic sites demonstrated complete pulp regeneration $[5,6]$. Subsequently, colony-derived DPSCs with platelet-rich plasma/fibrin (PRP/PRF) showed similar successful results [7]. The safety and efficacy of autologous DPSC therapy were demonstrated in the preclinical study harnessing DPSCs mobilized (MDPSCs) with granulocytecolony stimulating factor (G-CSF) harvested in good manufacturing practice conditions [8]. Furthermore, a recent clinical study suggested autologous MDPSC transplantation may be safe and efficacious for pulp regeneration in humans [9]. The autologous DPSCs, however, have certain limitations to overcome, such as limited availability of human discarded teeth and the high cost of the safety and quality control tests of individual cell products before transplantation. The further potential disadvantages of the autologous mesenchymal stem cells (MSCs) are their decreased biological activity from older patients and altered intrinsic stem cell properties from patients with some systemic diseases including diabetes and rheumatoid arthritis [10]. Transplantation of autologous mobilized adiposederived or bone marrow-derived MSCs resulted in lower volume of regenerated pulp tissue, less angiogenesis, and reinnervation compared with MDPSCs [11]. Furthermore, regenerated pulp tissues in adipose and bone marrow MSC transplants were more mineralized compared with MDPSC transplant, suggesting pulp MSCs were an optimal cell source for pulp regeneration. Thus, banked allogeneic DPSCs would be highly advantageous to save time and costs and to confirm high quality [12].

The use of allogeneic MSCs permits low immunogenicity with immunomodulatory and immunosuppressive properties. It is well known that MSCs have low immunogenicity due to no expression of class II major histocompatibility complex (MHC-II) proteins, and low or modest expression of MHC-I proteins and costimulatory molecules such as CD40, CD80, and CD86 on their cell surface $[13,14]$. Therefore, MSCs are unable to provoke a cytotoxic effect by allogeneic immune cells [15], and MSCs from MHC-mismatched donors may also be used for cell therapy [16]. Many studies recently focused on mechanisms of immunomodulation and immunosuppression of MSCs, especially in reducing inflammation, escaping from immune cell response, and modulating $\mathrm{T}$ cell proliferation. MSCs can interfere with different pathways of the immune responses by means of direct cell-to-cell interactions and secretion of soluble factors such as transforming growth factor (TGF)- $\beta$, hepatocyte growth factor (HGF), prostaglandin E2 (PGE2), nitric oxide (NO), indoleamine-2,3 dioxygenase (IDO), tumor necrosis factor (TNF)- $\alpha$ stimulated gene-protein 6 , interleukin (IL)-6, IL-10, semaphorin-3A, galectin (Gal)-1, and Gal-9 [17-20]. MSCs also possess the ability to generate regulatory $\mathrm{T}$ cells (Tregs) which suppress other immune cells [21, 22]. The whole range of mechanisms of immunomodulation and immunosuppression mediated by MSCs remains incompletely understood. The immunosuppressive and immunomodulatory responses are, however, properties shared by MSCs from a variety of adult and fetal tissues including dental pulp [18, 23].

A number of animal experiments have demonstrated that allogeneic MSCs improve acute myocardial infarction, chronic spinal cord injury, ischemic stroke, fracture healing, and osteoarthritis by local injection or intravenous infusion [24-28]. No adverse effects have been noticed in 291 equine recipients over a period of up to 1 year after intravenous injection of allogeneic peripheral blood-derived MSCs [29]. On the other hand, MHC class I mismatched MSCs induced $\mathrm{CD} 8^{+\mathrm{VE}}, \mathrm{CD} 16^{+\mathrm{VE}}$, and $\mathrm{CD} 8^{+\mathrm{VE}} / \mathrm{CD} 16^{+\mathrm{VE}}$ lymphocyte subpopulations, dependent on the dose of administered MSCs in intracranial injection and the degree of antigenic mismatch between donor and recipient [30]. Allogeneic bone marrow MSC transplantation into infarcted rat myocardium improved ventricular function for 3 months and a delayed immune rejection/response has been reported within 5 months due to the shift from a hypoimmunogenic to an immunogenic state of the transplanted MSCs upon differentiation [31]. Thus, consistent results have not yet been obtained on the therapeutic effects of allogeneic MSCs, depending on routes, timing duration, and dosage of MSC administration in vivo [10].

It is desirable for MSC transplantation into the root canal of the tooth to be repeated for pulp regeneration in patients with multiple caries. Repeated injection of allogeneic adipose tissue-derived MSCs (AT-MSCs) or bone marrow-derived MSCs (BM-MSCs) demonstrated a lack of adverse effects. However, repeated BM-MSC injections resulted in an increase in blood $\mathrm{CD}^{+} \mathrm{T}$-cell numbers and splenic regulatory $\mathrm{T}$-cell numbers 
compared with AT-MSCs in healthy horses, indicating a mild alloantigen-directed cytotoxic response [32]. Repeated intravenous injection of allogeneic porcine bone marrow MSCs or human umbilical cord blood-derived MSCs also induced no immunological alterations including T-cell proliferation, high levels of IFN- $\gamma$, TNF- $\alpha$, and human IgG and no adverse events due to low immunogenicity [33, 34]. Dual allogeneic MSC treatment by transepicardial injection in the acute and the subacute period after myocardial infarction improved ventricular function with increased myocardial mass and anteriolar density more than single MSC treatment in rats [35].

There are no reports on MHC-mismatched allogeneic transplantation and on dual allogeneic MSC transplantation in pulp regenerative therapy. Thus, there is a need to address challenges to allogeneic MDPSC cell therapy for total pulp regeneration. The aim of this investigation is to assess the safety and efficacy of allogeneic transplantation of canine MDPSCs into the pulpectomized tooth. The dual consecutive transplantation was further evaluated for safety and efficacy compared with the single transplantation.

\section{Methods}

Dog leukocyte antigen genotyping and matching analysis We used beagle dogs (Kitayama Labes, Iwakuni and Ina, Japan) owned by Shin Nippon Kagaku Biomedical Laboratories Ltd $(n=26)$. Total genomic DNA was extracted from whole blood of dogs by NuclesaseMag ${ }^{\circ} 96$ Blood (Marcherey-Nagel, Düren, Germany) according to the protocol. All of the dogs in the investigation were not in a sibling relationship. Genotyping was performed by direct sequencing and sequencing of the polymerase chain reaction (PCR) product. PCR was performed using primers $D L A-88$ exon 1-3 (1100 bp), DLA-DQA exon 2 (300 bp), DLA-DQB exon 2 (350 bp), and DLA-DRB exon 2 (350 bp) [36, 37] (Table 1) with KOD Fx (TOYOBO Co., Ltd, Osaka, Japan) in a GeneAmp PCR system 9700 (Thermo Fisher Scientific K.K., Yokohama,

Table 1 Primers of polymerase chain reaction for dog leukocyte antigen (DLA) genotyping

\begin{tabular}{lll}
\hline Gene & & 5'-3' DNA sequence \\
\hline DLA-88 exon 1-3 & Forward & AGTCCAGCGGCGACGGCCAGTGT \\
& CCCCGGA & AGCCCTCCCTAGTGGAGGCGAGA \\
& Reverse & TCGGGGA \\
DLA-DQA exon 2 & Forward & TAAGGTCTTTCTCCCTCT \\
& Reverse & GG AC AG ATT C AGT G AAG AG A \\
DLA-DQB exon 2 & Forward & CTCACTGGCCCGGCTGTCTC \\
& Reverse & GGTGCGCTCACCTCGCCGCT \\
DLA-DRB exon 2 & Forward & GATCCCCCCGTCCCCACAG \\
& Reverse & TGTGTCACACACCTCAGCACCA \\
\hline
\end{tabular}

Japan). PCR products were subcloned into a ZeroBlunt TOPO PCR Cloning Kit (Thermo Fisher Scientific K.K.). Sequencing was carried out using a ABI PRISM BigDye Terminator v3.0 Ready Reaction Cycle Sequencing Kit (Thermo Fisher Scientific K.K.) with an ABI PRISM 3730 DNA Analyzer (Thermo Fisher Scientific K.K.), and the raw data were analyzed by Sequencer Ver 4.8 (Gene Codes Corp., Ann Arbor, MI, USA). The allele names were determined according to the universal nomenclature found in the Immuno Polymorphism Database (EMBL-EBI, Cambridge, UK).

\section{Cell isolation and culture}

Upper left lateral incisors were freshly extracted from each beagle dog at 8 months of age. After making a longitudinal cut, they were transported by air within $30 \mathrm{~h}$ to the National Center for Geriatrics and Gerontology (NCGG) from Shin Nippon Biomedical Laboratories Ltd, Drug Safety Research Laboratories (Kagoshima, Japan), and RaQualia Pharma Inc. (Rental Laboratories of NCGG) in Hank's balanced salt solution (Invitrogen, Carlsbad, CA, USA) with $2.5 \mathrm{mg} / \mathrm{ml}$ amphotericin B (Bristol-Myers Squibb, Tokyo, Japan) and $0.3 \%$ gentamicin (Nitten, Nagoya, Japan). Mobilized dental pulp stem cells (MDPSCs) were isolated using the similar procedure used for a previous autologous preclinical study [8]. In brief, dental pulp tissues isolated from the teeth were enzymatically digested in $0.04 \mathrm{mg} / \mathrm{ml}$ Liberase (Roche, Mannheim, Germany) for $30 \mathrm{~min}$ at $37{ }^{\circ} \mathrm{C}$. The isolated pulp cells were plated at $2 \times 10^{4}$ cells on T-25 (Asahi Technoglass, Funabashi, Japan) in Dulbecco's Modified Eagle's Medium (DMEM) (Sigma, St. Louis, MO, USA) supplemented with $10 \%$ autologous canine serum, $2.5 \mathrm{mg} / \mathrm{ml}$ amphotericin B, and $0.3 \%$ gentamicin. They were detached by incubation with TrypLE ${ }^{\mathrm{rm}}$ Select (Invitrogen) prior to $70 \%$ confluence. The colony-formed DPSCs were further isolated by GCSF-induced stem cell mobilization method with G-CSF (Neutrogin; Chugai Pharmaceutical Co., Ltd, Tokyo, Japan) at $100 \mathrm{ng} / \mathrm{ml}$, with $2 \times 10^{4}$ cells $/ 100 \mu \mathrm{l}$ on the Transwell (Corning, Lowell, MA, USA), and inserted into 24-well tissue culture plates for 48-h incubation [38]. The isolated MDPSCs were detached by incubation with Try$\mathrm{pLE}^{\mathrm{Tm}}$ Select at $60-70 \%$ confluence and subcultured at a 1: 3 dilution into cell culture flasks $\left(25 \mathrm{~cm}^{2}\right.$ and further $75 \mathrm{~cm}^{2}$ ) (Asahi Technoglass) in DMEM supplemented with $10 \%$ autologous canine serum without antibiotics. The cells were cryopreserved at a cell concentration of $1 \times 10^{6}$ cells $/ \mathrm{ml}$ in an extracellular cryoprotectant (CP-1; Kyokuto Pharmaceutical Industrial Co., Ltd, Tokyo, Japan) at the 7 th passage of culture.

\section{Characterization of mobilized dental pulp stem cells}

The quality of cryopreserved MDPSCs was confirmed by cell viability and proliferation abilities at the 7 th passage 
of culture. In brief, the cells stained with trypan blue (Sigma-Aldrich, St. Louis, MO, USA) were counted following thawing for the cell viability test, further plated at $2.0 \times 10^{5}$ cells in $10-\mathrm{cm}$ dishes (Corning, NY, USA), and proliferation rates were calculated at $48 \mathrm{~h}$ as the doubling time.

To further characterize the immunomodulation ability of MDPSCs, mobilized adipose-derived stem cells (MADSCs) were isolated from the abdominal subcutaneous adipose tissue [11] from the same individual dog similarly to MDPSCs as already described for comparison with MDPSCs. Total RNA was extracted with TRIzol (Life Technologies). First-strand cDNA syntheses were performed on the total RNA of these cells by reverse transcription using ReverTra Ace-a (Toyobo, Tokyo, Japan) after DNase I treatment (Roche Diagnostics) at $37^{\circ} \mathrm{C}$ for $20 \mathrm{~min}$. Real-time RT-PCR was performed using primers for the immunomodulatory factors (Table 2) prostaglandin E synthase (PTGES), cyclooxygenase-2 (COX-2), IL-6, TGF- $\beta$ and indoleamine 2, 3-dioxygenase-1 (IDO-1) labeled with AmpliTaq Gold master mix (Thermo Fisher Scientific) in an Applied Biosystems ${ }^{\circ} 7500$ Real-Time PCR (Life Technologies). After normalizing with $\beta$-actin, the mRNA level of each immunomodulatory factor in MDPSCs was compared with that in MADSCs derived from the same individual $\operatorname{dog}(n=3)$.

\section{Evaluation of safety of first and second allogeneic transplantation for pulp regeneration}

The cryopreserved MDPSCs were transported by air to the operating room of the animal facility in Shin Nippon Biomedical Laboratories Ltd under strict temperature control. One day before transplantation, the root canal was open to the apex with a \#25 K file after pulpectomy and shaped to $0.55 \mathrm{~mm}$ in width, $0.5 \mathrm{~mm}$ from the apex in the upper right lateral incisors in 14 dogs. For the first allogeneic transplantation, the dog leukocyte antigen (DLA) matched and mismatched MDPSCs $(n=5$, respectively) were transplanted into the root canal, $5 \times 10^{5}$ cells together with $20 \mu \mathrm{l}$ of collagen scaffold (atelocollagen implant; Koken, Tokyo, Japan) and 150 ng of G-CSF (Neutrogin), respectively (Fig. 1). For toxicology assessment, clinical signs of dogs were observed and their food consumption was measured daily, and their weights were recorded weekly. Urine chemistry examinations by Clinitek AtlasXL (Sparton Medical Systems, Strongsville, OH, USA) were performed at 4 and 12 weeks, and blood tests by ADIVIA 120 (Siemens Healthcare Diagnostics Manufacturing Ltd, Erlangen, Germany) and blood chemistry examinations by JCA-BM6070 (Japan Electron Optical Laboratory, Tokyo, Japan) were performed at 4 and 12 weeks after transplantation. Blood tests demonstrate the red blood cell count (RBC) and hematocrit (Ht) for homeostasis of blood cells, the platelet count (Plt) for inflammation, and the white blood cell count (WBC) for inflammation and infection. Blood chemistry examinations demonstrate aspartate transaminase (AST) and alanine transaminase (ALT) for abnormality of the liver, albumin and globulin for protein metabolism, total cholesterol (Tcho) for the lipid profile, and glucose for abnormality of hormone. After extraction of the upper right lateral incisors at 12 weeks, the second allogeneic transplantation of the same matched and mismatched MDPSCs as the first transplantation was performed in pulpectomized lower right third incisors in the same dogs, respectively $(n=5)$. The safety tests were further performed at 4 and 12 weeks. The transplanted teeth were extracted at 24 weeks followed by euthanization. All organs were weighed and macroscopically examined. Furthermore, histopathological examination of all organs and tissues including the transplanted teeth with surrounding periodontal tissue were also

Table 2 Canine primers for real-time reverse transcription-polymerase chain reaction for immunomodulatory factors

\begin{tabular}{|c|c|c|c|c|}
\hline Gene & & 5'-3' DNA sequence & Accession number & Product (base pairs) \\
\hline \multirow[t]{2}{*}{ PTGES } & Forward & GCCGCTGTGACTGTACC & NM_001122854 & 190 \\
\hline & Reverse & TGGTCCAATCAGCCACTTC & & \\
\hline \multirow[t]{2}{*}{$\operatorname{cox}-2$} & Forward & GTTCATTCCTGATCCCCAAG & NM_001003354 & 186 \\
\hline & Reverse & TTGAAAAGGCGCAGTTTATG & & \\
\hline \multirow[t]{2}{*}{ IL-6 } & Forward & TCCAGAACAACTATGAGGGTGA & NM_001003301.1 & 100 \\
\hline & Reverse & TCCTGATTCTTTACCTTGCTCTT & & \\
\hline \multirow[t]{2}{*}{ TGF- $\beta$} & Forward & CTGGAGTCGTGAGGCAGTG & NM 0010033309.1 & 96 \\
\hline & Reverse & GCAGTGTGTTATCTTTGCTGTCA & & \\
\hline \multirow[t]{2}{*}{ IDO-1 } & Forward & GGAAAGGCAACTCCAAACTG & XM_532793 & 124 \\
\hline & Reverse & CCCAGCAGAATGTCAAAGC & & \\
\hline \multirow[t]{2}{*}{$\beta$-actin } & Forward & AAGTACCCCATTGAGCACGG & Z70044 & 257 \\
\hline & Reverse & ATCACGATGCCAGTGGTGCG & & \\
\hline
\end{tabular}




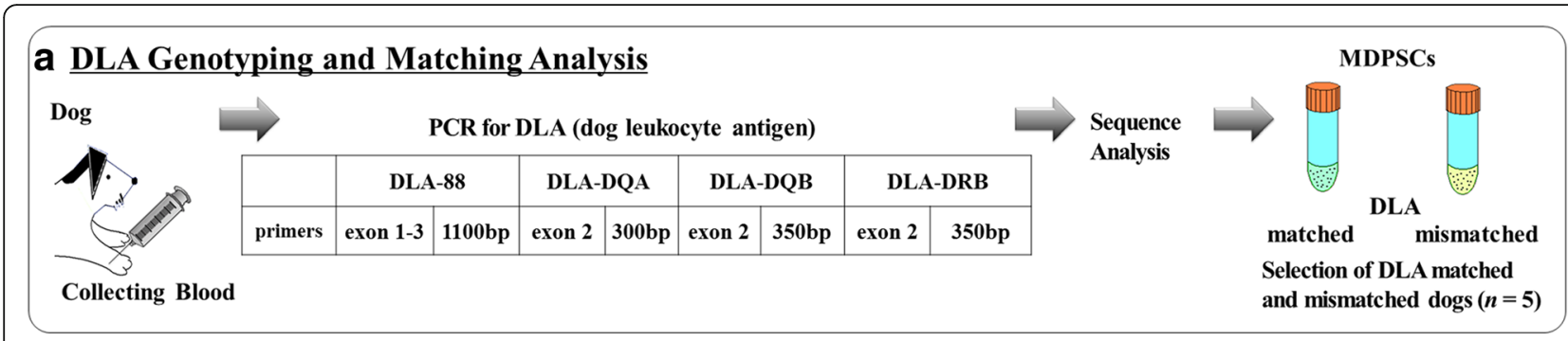

\section{b Dual Transplantation of Allogeneic MDPSCs in pulpectomized teeth in Dogs}
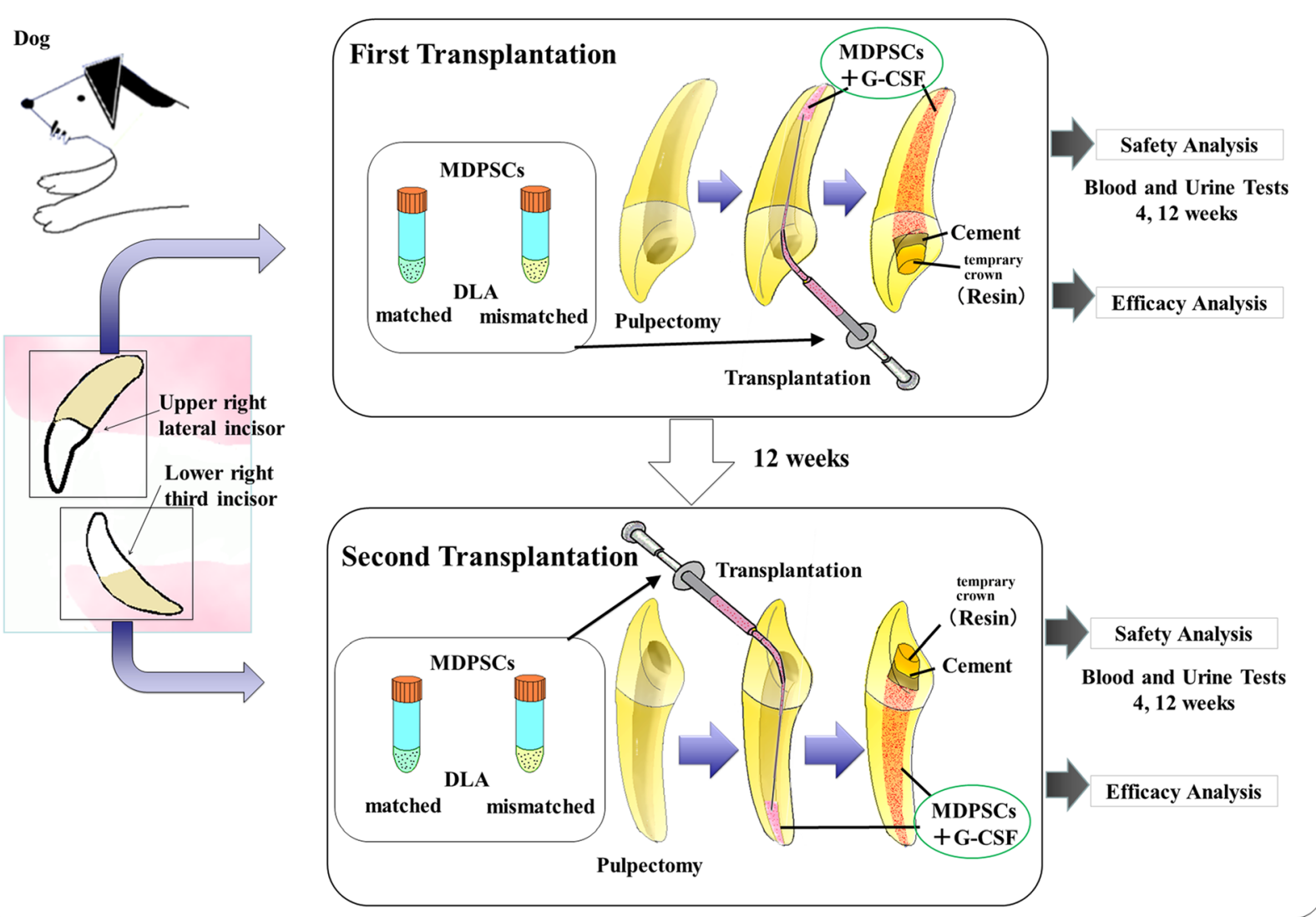

Fig. 1 Schematic diagram of allogeneic pulp regeneration after transplantation of mobilized dental pulp stem cells (MDPSCs) in a canine pulpectomy model in teeth. a Analysis of allele profiles. Dog leukocyte antigen (DLA) genotyping and matching analysis from whole blood of dogs. $\mathbf{b}$ Dual transplantation of allogeneic MDPSCs in pulpectomized teeth in dogs. First transplantation: DLA matched and mismatched MDPSCs transplanted in the upper right lateral incisors. Safety and efficacy analyses performed at 4 and 12 weeks and at 12 weeks, respectively. Second transplantation: the same matched and mismatched MDPSCs as the first transplantation transplanted in the lower right third incisors in the same dogs. At 12 weeks after second transplantation, histological examination of all organs including the transplanted teeth and surrounding periodontal tissue performed for the safety test in addition to the same safety and efficacy test as the first transplantation. PCR polymerase chain reaction, G-CSF granulocyte colony-stimulating factor, temprary crown

performed in the paraffin sections stained with hematoxylin and eosin (HE).

Efficacy of first and second allogeneic transplantation for pulp regeneration

Morphological examination of the regenerated tissue was performed in the paraffin sections $(5 \mu \mathrm{m}$ in thickness) of the teeth. The relative amounts of regenerated tissue were measured in the sections of the first transplants of matched $(n=5)$ and mismatched MDPSCs $(n=5)$, and the second transplants of matched $(n=4)$ and mismatched MDPSCs $(n=5)$. On-screen image outlines of regenerated tissue in the root canals were traced by capturing images of the histological preparations on a 
binocular microscope (M 205 FA; Leica) and the surface area of these outlines was determined using Leica Application Suite software (version 3.4.1; Leica).

For neovascularization and innervations analyses, 5$\mu \mathrm{m}$-thick paraffin sections were deparaffinized and stained with Fluorescein Griffonia (Bandeiraea) Simplicifolia Lectin 1/fluorescein-galanthus nivalis (snowdrop) lectin (BS-1 lectin) (20 $\mu \mathrm{g} / \mathrm{ml}$; Vector laboratories, Inc., Youngstown, OH, USA) and anti-PGP9.5 (Ultra Clone) (1:10,000), respectively, as described previously [6]. The ratios of the BS-1 lectin-positive newly formed capillaries were calculated respectively using a Dynamic cell count BZ-HIC (KEYENCE, Osaka, Japan) in the first transplants of matched $(n=4)$ and mismatched MDPSCs $(n=4)$, and in the second transplants of matched $(n=5)$ and mismatched $(n=5)$ MDPSCs.

For quantitative analysis of matrix formation, the sections from each four teeth at 12 weeks after the first and second transplantation of matched and mismatched MDPSCs were stained with Masson trichrome staining (Muto Pure Chemicals Co., Ltd, Tokyo, Japan). The relative amounts of matrix formation area were measured in the sections of the first transplants of matched $(n=5)$ and mismatched MDPSCs $(n=5)$, and the second transplants of matched $(n=4)$ and mismatched MDPSCs $(n=3)$. On-screen image outlines were traced by capturing images of the histological preparations on a binocular microscope (M 205 FA; Leica). The positive area was quantitatively analyzed using Leica Application Suite software (version 3.4.1; Leica).

\section{Statistical analyses}

Data are reported as mean \pm SD. $P$ values were calculated using Tukey's multiple comparison test method in SPSS 21.0 (IBM, Armonk, NY, USA).

\section{Results \\ DLA analysis}

DLA genotyping and matching analyses in 26 dogs demonstrated a four homozygous allele profile (nine dogs), a three homozygous and one heterozygous allele profile (three dogs), a two homozygous and two heterozygous allele profile (four dogs), a one homozygous and three heterozygous allele profile (one dog), and a four heterozygous allele profile (nine dogs). In the four homozygous allele profile group, eight dogs had eight completely matched alleles (Group A) out of nine dogs. In the two homozygous and two heterozygous allele profile group, four dogs had seven matched alleles. In the four heterozygous haplotype group, four dogs had seven matched alleles (Group B) out of nine dogs (Table 3). We selected five identical and almost identical donors of the allele profiles (four dogs from Group A, one dog from Group B) and five nonidentical donors with at least four mismatched alleles for allogeneic transplantation (Table 4).

\section{The isolated canine MDPSCs}

The isolated and cryopreserved MDPSCs at the 7th passage of culture were stellate with short processes or spindle-shaped. The cell viability was more than $90 \%$ following thawing of the frozen cells. The doubling time was approximately $30 \mathrm{~h}$ as previously isolated from canine teeth transported by land within $1 \mathrm{~h}$ [9], suggesting that the transportation of the extracted teeth by air within $30 \mathrm{~h}$ did not affect the cell proliferation ability. The mRNA expression levels of PTGES, COX-2, IL-6, TGF- $\beta$, and IDO-1 were similar in MDPSCs and MADSCs derived from the same individual dog (Table 5), suggesting similar immunomodulatory/immunosuppressive function of MDPSCs to MADSCs.

\section{Safety of allogeneic transplantation}

Toxicology assessment showed no adverse effects on appearance, clinical signs, food consumption, and body weight for 12 weeks after allogeneic first transplantation of the MDPSCs from four DLA-nonidentical donors as well as those from three DLA-identical and one almost DLA-identical donors. The blood test demonstrated no increase of white blood cell and platelet numbers (Table 6), demonstrating no alloreaction toward the transplanted cells. Serum and urine chemistry parameters showed values within normal ranges at 4 and 12 weeks after both first and second allogeneic transplantation (Table 6). Furthermore, there was also no evidence of toxicity or adverse events at 4 and 12 weeks after second DLA-nonidentical and DLA-identical transplantation of the same type of MDPSCs as in the first transplantation. No abnormalities were caused by the allogeneic transplantation in any organ or tissues assessed by histopathological examinations at 12 weeks after the second transplantation. These results demonstrate that DLA mismatched transplantation might be safe for pulp regeneration for 12 weeks in dogs not only the first time but also the second time.

\section{Pulp regeneration after allogeneic transplantation}

We next compared the regenerated tissue after DLA mismatched MDPSC transplantation with matched MDPSC transplantation into the pulpectomized root canal (Fig. 2). Pulp-like tissues with well-developed vasculature were observed at 12 weeks in both the allogeneic first transplants (Fig. 2a, b, d, e and Additional file 1: Figure S1). Similar pulp-like tissues in cell morphology, cell density, and architecture of the extracellular matrix with a few inflammatory cells were also regenerated at 12 weeks in both the DLA mismatched and matched second transplants (Fig. 2g, h, j, k). Odontoblast-like cells with a long process 
Table 3 Dog leukocyte antigen (DLA) analysis of the 26 individual dogs

\begin{tabular}{|c|c|c|c|c|c|c|c|c|c|c|c|}
\hline \multirow{3}{*}{$\begin{array}{l}\text { Group } \\
\mathrm{A}\end{array}$} & \multirow{3}{*}{$\begin{array}{l}\begin{array}{l}\text { Animal } \\
\text { number }\end{array} \\
\text { 13MW } 302\end{array}$} & \multirow{3}{*}{$\begin{array}{l}\text { Gender } \\
\text { Male }\end{array}$} & \multirow{2}{*}{\multicolumn{2}{|c|}{$\frac{\text { DLA-88 }}{\text { exon 1-3 (ll00 bp) }}$}} & \multirow{2}{*}{\multicolumn{2}{|c|}{$\frac{\text { DLA-DQA }}{\text { exon } 2 \text { (300 bp) }}$}} & \multirow{2}{*}{\multicolumn{2}{|c|}{$\frac{\text { DLA-DQB }}{\text { exon } 2 \text { (350 bp) }}$}} & \multirow{2}{*}{\multicolumn{2}{|c|}{$\frac{\text { DLA-DRB }}{\text { exon } 2 \text { (350 bp) }}$}} & \multirow{3}{*}{$\begin{array}{l}\text { Haplotype } \\
4 \text { homo }\end{array}$} \\
\hline & & & & & & & & & & & \\
\hline & & & *50201 & *50201 & ${ }^{*} 00101$ & ${ }^{*} 00101$ & *00201 & ${ }^{*} 00201$ & ${ }^{*} 00102$ & ${ }^{*} 00102$ & \\
\hline A & $13 \mathrm{MW} 320$ & Male & *50201 & *50201 & *00101 & ${ }^{*} 00101$ & ${ }^{*} 00201$ & ${ }^{*} 00201$ & ${ }^{*} 00102$ & ${ }^{*} 00102$ & 4 homo \\
\hline A & 13MW1036 & Male & *50201 & *50201 & *00101 & *00101 & ${ }^{*} 00201$ & ${ }^{*} 00201$ & ${ }^{*} 00102$ & ${ }^{*} 00102$ & 4 homo \\
\hline A & BMW 1052 & Male & *50201 & *50201 & *00101 & *00101 & ${ }^{*} 00201$ & ${ }^{*} 00201$ & ${ }^{*} 00102$ & *00102 & 4 homo \\
\hline A & 13FW 191 & Female & *50201 & *50201 & ${ }^{*} 00101$ & ${ }^{*} 00101$ & *00201 & ${ }^{*} 00201$ & ${ }^{*} 00102$ & ${ }^{*} 00102$ & 4 homo \\
\hline A & 13FW283 & Female & *50201 & *50201 & ${ }^{*} 00101$ & ${ }^{*} 00101$ & ${ }^{*} 00201$ & ${ }^{*} 00201$ & ${ }^{*} 00102$ & ${ }^{*} 00102$ & 4 homo \\
\hline A & 13FW 956 & Female & *50201 & *50201 & ${ }^{*} 00101$ & *00101 & *00201 & ${ }^{*} 00201$ & ${ }^{*} 00102$ & ${ }^{*} 00102$ & 4 homo \\
\hline A & 13FW 976 & Female & *50201 & *50201 & ${ }^{*} 00101$ & ${ }^{*} 00101$ & ${ }^{*} 00201$ & ${ }^{*} 00201$ & ${ }^{*} 00102$ & ${ }^{*} 00102$ & 4 homo \\
\hline & 13MW1149 & Male & $* 11$ & $* 11$ & ${ }^{*} 00101$ & ${ }^{*} 00101$ & ${ }^{*} 00201$ & ${ }^{*} 00201$ & ${ }^{*} 00101$ & ${ }^{*} 00101$ & 4 homo \\
\hline & BMW 273 & Male & ${ }^{*} 02501$ & ${ }^{*} 16 a$ & ${ }^{*} 005011$ & ${ }^{*} 005011$ & ${ }^{*} 00701$ & ${ }^{*} 00701$ & ${ }^{*} 02801$ & ${ }^{*} 02801$ & $\begin{array}{l}3 \text { homo } \\
1 \text { hetero }\end{array}$ \\
\hline & 13FW 1026 & Female & *50201 & *50801 & *00101 & *00101 & *00201 & ${ }^{*} 00201$ & ${ }^{*} 00102$ & *00102 & $\begin{array}{l}3 \text { homo } \\
1 \text { hetero }\end{array}$ \\
\hline & 13FW300 & Female & *50201 & *50201 & ${ }^{*} 00101$ & ${ }^{*} 00101$ & *00201 & ${ }^{*} 00201$ & ${ }^{*} 00101$ & ${ }^{*} 00102$ & $\begin{array}{l}3 \text { homo } \\
1 \text { hetero }\end{array}$ \\
\hline & BMW 318 & Male & *50201 & *50801 & ${ }^{*} 00101$ & ${ }^{*} 00101$ & *00201 & ${ }^{*} 00201$ & ${ }^{*} 00101$ & ${ }^{*} 00102$ & $\begin{array}{l}2 \text { homo } \\
2 \text { hetero }\end{array}$ \\
\hline & 13FW 992 & Female & *50201 & *50801 & *00101 & ${ }^{*} 00101$ & *00201 & ${ }^{*} 00201$ & ${ }^{*} 00101$ & ${ }^{*} 00102$ & $\begin{array}{l}2 \text { homo } \\
2 \text { hetero }\end{array}$ \\
\hline & 13FW 299 & Female & *50201 & $* 11$ & *00101 & ${ }^{*} 00101$ & ${ }^{*} 00201$ & ${ }^{*} 00201$ & ${ }^{*} 00101$ & *00102 & $\begin{array}{l}2 \text { homo } \\
2 \text { hetero }\end{array}$ \\
\hline & 13FW1031 & Female & *50201 & $* 11$ & ${ }^{*} 00101$ & ${ }^{*} 00101$ & *00201 & ${ }^{*} 00201$ & ${ }^{*} 00101$ & ${ }^{*} 00102$ & $\begin{array}{l}2 \text { homo } \\
2 \text { hetero }\end{array}$ \\
\hline & 13FW281 & Female & *50201 & *50201 & *00101a & ${ }^{*} 00301$ & *00201 & ${ }^{*} 00401$ & ${ }^{*} 00102$ & ${ }^{*} 00801$ & $\begin{array}{l}1 \text { homo } \\
3 \text { hetero }\end{array}$ \\
\hline B & BMW 223 & Male & *01201 & *50201 & *00101 & ${ }^{*} 00901$ & *00101 & ${ }^{*} 00201$ & ${ }^{*} 00102$ & *01501 & 4 hetero \\
\hline B & 13MW1133 & Male & *01201 & *50201 & *00101 & *00901 & *00101 & ${ }^{*} 00201$ & *00102 & *01501 & 4 hetero \\
\hline B & BMW 1029 & Male & *01201 & *50801 & ${ }^{*} 00101$ & ${ }^{*} 00901$ & ${ }^{*} 00101$ & ${ }^{*} 00201$ & ${ }^{*} 00102$ & ${ }^{*} 01501$ & 4 hetero \\
\hline B & 13FW 926 & Female & *01201 & $* 21$ & ${ }^{*} 00101$ & ${ }^{*} 00901$ & ${ }^{*} 00101$ & ${ }^{*} 00201$ & ${ }^{*} 00102$ & *01501 & 4 hetero \\
\hline & 13MW1135 & Male & *01201 & $* 11$ & *00101 & *00901 & *00101 & ${ }^{*} 00201$ & *00101 & *01501 & 4 hetero \\
\hline & BMW 1086 & Male & *50201 & $* 11$ & ${ }^{*} 00101$ & ${ }^{*} 00301$ & ${ }^{*} 00201$ & ${ }^{*} 00401$ & ${ }^{*} 00101$ & ${ }^{*} 00801$ & 4 hetero \\
\hline & 13FW1019 & Female & *50201 & *50801 & ${ }^{*} 00101$ & ${ }^{*} 00901$ & *00101 & ${ }^{*} 00201$ & ${ }^{*} 00102$ & ${ }^{*} 00201$ & 4 hetero \\
\hline & 13FW 995 & Female & *50801 & $* 11$ & *00101 & *00201 & ${ }^{*} 00201$ & ${ }^{*} 01303$ & ${ }^{*} 00101$ & ${ }^{*} 00102$ & 4 hetero \\
\hline & 13MW1122 & Male & ${ }^{*} 02501$ & *50201 & ${ }^{*} 00101$ & ${ }^{*} 005011$ & ${ }^{*} 00201$ & ${ }^{*} 00701$ & ${ }^{*} 00101$ & ${ }^{*} 02801$ & 4 hetero \\
\hline
\end{tabular}

$b p$ base pairs, homo homozygous, hetero heterozygous, * indicate alleles, "a" indicates the closest matching allele

and osteodentinoblast-like cells were attached to the wall of newly formed osteo/tubular dentin (Fig. 2c, f, i, m) and neither inflammation nor internal/external resorption was detected (Fig. 2j, n). The regenerated tissue was filled in the root canal more than $80 \%$ to the dentin-enamel junction in all four transplants. The statistical analysis demonstrated no difference among the four transplants (Fig. 2o). Vascularization demonstrated by BS-1 lectin staining was also similar in density and orientation in the four groups of transplants (Fig. 3a-d), and there was no significant differences in the capillary density among them (Fig. 3e).
Nerve fibers stained by PGP9.5 antibody were similarly observed, indicating similar reinnervation (Fig. 3f-i). Dentin-like mineralized tissue formation was similarly observed along the dentinal wall (Fig. $3 \mathbf{j}-\mathrm{m}$ ). There was no significant difference in the matrix formation among the four transplants by morphometric analysis of the Masson trichrome positively stained area (Fig. 3n). These results suggest no qualitative and quantitative differences in the regenerated tissue between the DLA mismatched and matched transplants and between first and second transplants. 
Table 4 Dog leukocyte antigen (DLA) matched and mismatched MDPSC transplantation for safety and efficacy tests

\begin{tabular}{|c|c|c|c|c|c|}
\hline \multicolumn{3}{|l|}{ Recipient dogs } & \multicolumn{2}{|c|}{ Donor dogs of transplanted MDPSCs } & \multirow{2}{*}{$\begin{array}{l}\text { Matched/ } \\
\text { mismatched }\end{array}$} \\
\hline Individual number & DLA type & Gender & Individual number & DLA type & \\
\hline 13MW 302 & 4 homo & Male & BMW 320 & 4 homo & Complete matched \\
\hline 13FW 191 & 4 homo & Female & 13FW283 & 4 homo & Complete matched \\
\hline 13FW 283 & 4 homo & Female & 13FW 191 & 4 homo & Complete matched \\
\hline 13FW 956 & 4 homo & Female & 13FW 976 & 4 homo & Complete matched \\
\hline 13MW 1029 & 4 hetero & Male & BMW 1133 & 4 hetero & Matched \\
\hline 13FW300 & 3 homo 1 hetero & Female & BMW 273 & 3 homo 1 hetero & Mismatched \\
\hline 13FW 299 & 2 homo 2 hetero & Female & BMW 223 & 4 hetero & Mismatched \\
\hline 13FW1031 & 2 homo 2 hetero & Female & 13FW 1122 & 4 hetero & Mismatched \\
\hline 13FW926 & 4 hetero & Female & 13FW 1031 & 2 homo 2 hetero & Mismatched \\
\hline 13MW 1122 & 4 hetero & Male & BMW 1149 & 4 homo & Mismatched \\
\hline
\end{tabular}

MPDSC mobilized dental pulp stem cell, homo homozygous, hetero heterozygous

\section{Discussion}

The aim of the present investigation was to evaluate the safety and efficacy of allogeneic transplantation of DLA matched and mismatched MDPSCs in pulpectomized teeth with complete apical closure for pulp/dentin regeneration in dogs. A crucial challenge, however, is the limitation of genotyping major histocompatibility with relevance for humans using animal models in a preclinical study. The dog is a suitable animal model for pulp regenerative therapy, where the incisor tooth and its dental pulp tissue are similar in anatomy and developmental biology to humans [39]. Tissue regeneration in the dog may also be influenced by similar factors as in humans, including the immune system [40] and genetics [41]. Thus, dogs have served as an effective, directly translatable model for MSC transplantation [42, 43]. Major histocompatibility complex (MHC) genes in mammals include class I and class II genes that are highly polymorphic and their donor-recipient matching is important for cell transplantation [43]. The genes for the dog MHC or DLA have been defined as a sequencebased nomenclature $[44,45]$. There are four complete class I genes: DLA-88, DLA-12, DLA-64, and DLA-79, in which DLA-88 is highly polymorphic (more than 72 alleles) and the others are less polymorphic. In the class

Table 5 Relative mRNA expression of immunomodulatory factors in MDPSCs compared with that in MADSCs

\begin{tabular}{ll}
\hline & MDPSC/MADSC \\
\hline PTGES & $2.6 \pm 3.5$ \\
COX-2 & $0.9 \pm 0.7$ \\
IL-6 & $1.3 \pm 0.6$ \\
TGF- $\beta$ & $1.6 \pm 0.7$ \\
IDO-1 & $1.5 \pm 1.9$ \\
\hline
\end{tabular}

MPDSC mobilized dental pulp stem cell, MADSC mobilized adipose derived stem cell, PTGES prostaglandin E synthase, COX-2 cyclooxygenase-2, IL interleukin, TGF transforming growth factor, IDO-1 indoleamine 2,3-dioxygenase 1
II region, there are DLA-DQA1 (nine alleles), DLADQB1 (20 alleles), DLA-DRB1 (at least 24 alleles), and DLA-DRA (monomorphic) [43, 46]. In the present work, DLA genotyping and matching analysis were performed in 26 dogs by PCR for the four genes orthologous to the human genes including DLA-88, DLA-DQA, DLA-DQB, and DLA-DRB [47]. The results demonstrated eight dogs with four completely matched alleles (four homozygous allele profile), four dogs with three completely matched alleles (two homozygous and two heterozygous allele profile), and four dogs with three completely matched alleles (four heterozygous allele profile). The similarity of the allele profiles was not due to related siblings, and all of the MDPSCs were transplanted into unrelated recipients. Based on an analysis of canine DLA diversity, the three-locus DLA haplotype, DQA1 00101;DQB1 00201; DRB1 00102 represented 40.3\% and DQA1 00101;DQB1 00201;DRB1 00101 represented $11.9 \%$ in the beagle [37], which is higher than the present rate: eight dogs out of $26(30.7 \%)$ and only one dog out of $26(3.8 \%)$, respectively, in the present study, suggesting the possibility of a distinct breed. The true extent of diversity of DLA genes in canines, especially of the class I gene DLA-88, however, is still unknown [43].

A variety of animal and human studies have demonstrated that stem cell-based therapy with allogeneic MSCs is a potential therapeutic option to regenerate damaged tissue/organ [10]. The low immunogenicity and immunomodulatory/immunosuppressive properties of allogeneic MSCs may contribute to a reduced immune response [48]. We have previously demonstrated lack of expression of $\mathrm{MHC}$ class II and costimulatory molecules, such as CD40, CD80 (B7-1), and CD86 (B72 ), although MHC-I is expressed in human MDPSCs [38]. We have also demonstrated that human and canine MDPSC conditioned medium inhibits allogeneic peripheral blood mononuclear cell (PBMC) proliferation and 


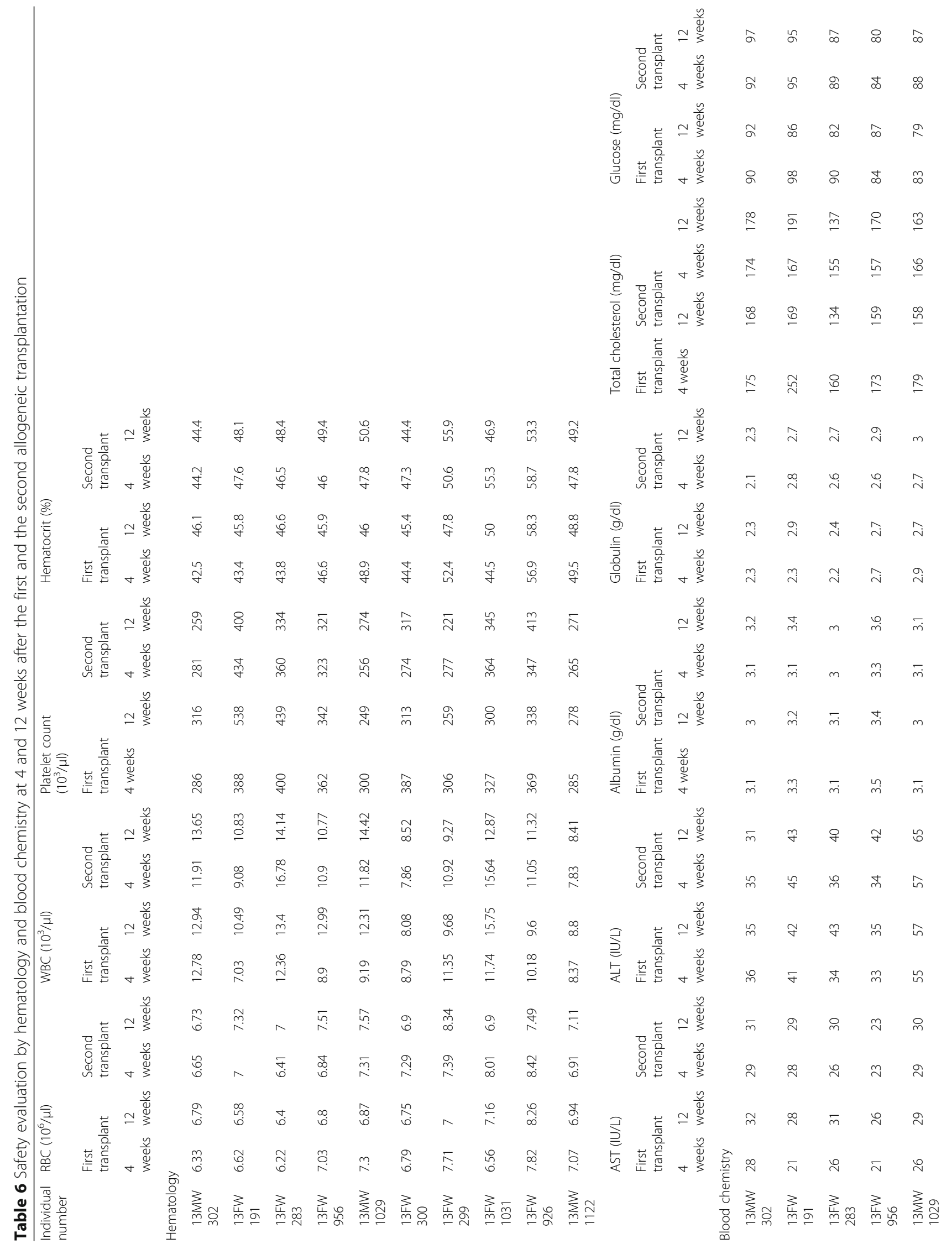




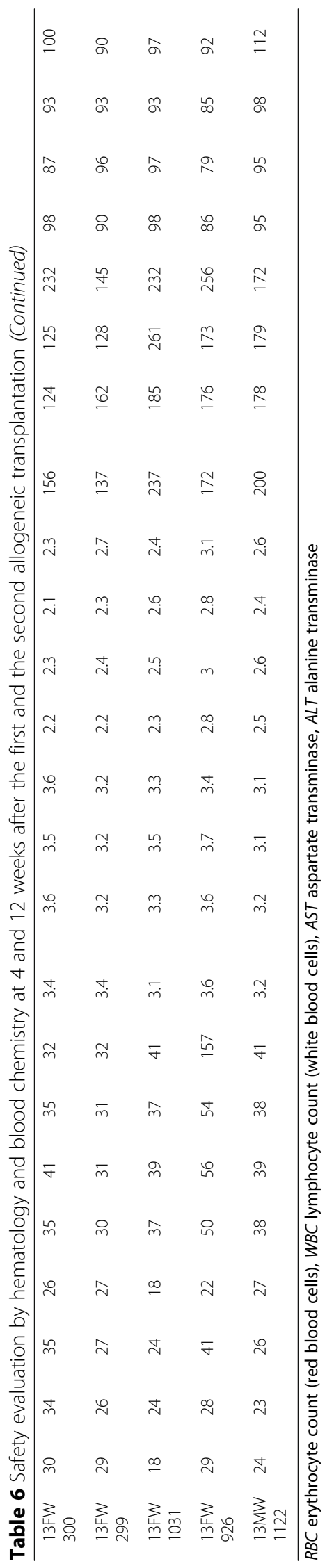



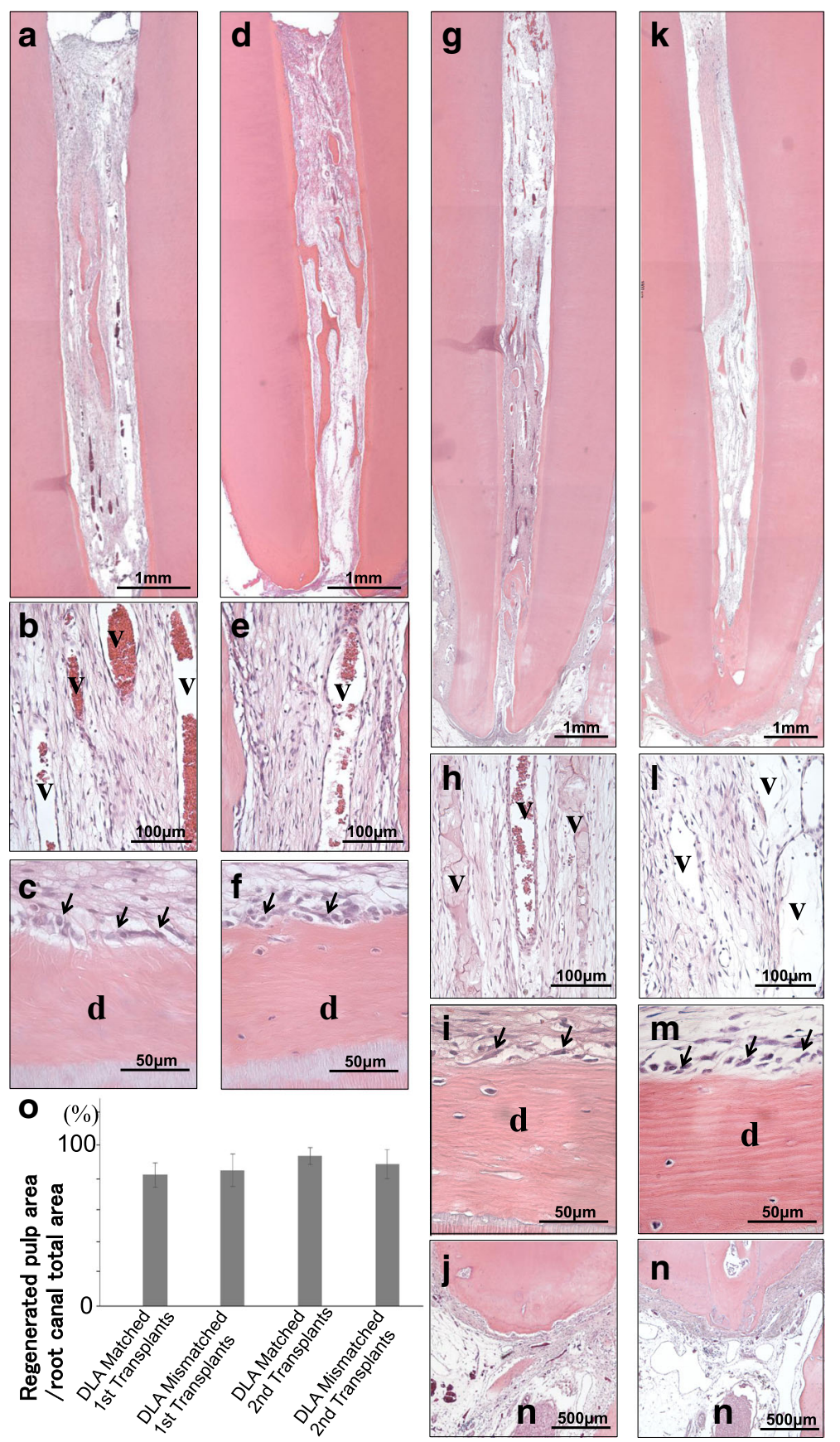

Fig. 2 Total pulp regeneration 12 weeks after allogeneic transplantation of mobilized dental pulp stem cells (MDPSCs) in pulpectomized teeth in dogs. a-f First transplantation. $\mathbf{g}-\mathbf{n}$ Second transplantation. $\mathbf{a}-\mathbf{c}, \mathbf{g}-\mathbf{j}$ DLA matched transplant. $\mathbf{d}-\mathbf{f}, \mathbf{k}-\mathbf{n}$ DLA mismatched transplant. b, e, h, I Newly formed blood vessels (v) in the regenerated tissue. $\mathbf{c}, \mathbf{f}, \mathbf{i}, \mathbf{m}$ Odontoblast-like cells (arrows) lining along with the wall of the newly formed osteodentin/tubular dentin (d). $\mathbf{j}, \mathbf{n}$ Periapical region of the transplanted teeth. Inferior alveolar nerve fiber bundle (n). Hematoxylin and eosin (HE) staining. o Morphometric statistical analysis. Ratio of newly regenerated area to root canal area. Data are mean \pm standard deviation $(n=5)$. Tukey's multiple comparison test method

demonstrates a dose-dependent inhibition of PBMC immune responses in mixed lymphocyte reaction (MLR) assays [8, 38], confirming the work in DPSCs [49]. IFN- $\gamma$ secreted by activated PBMCs induce the expression of soluble factors by DPSCs, which may play an important role in the immunosuppressive process [50]. Expression of PGE2, TGF- $\beta$, indolamine-2, 3-dioxygenase-1 (IDO1), IL-6, IL-10, and COX2 triggers the immunosuppressive activity of DPSCs [51-55]. The present study demonstrated that genes related to immunomodulation 

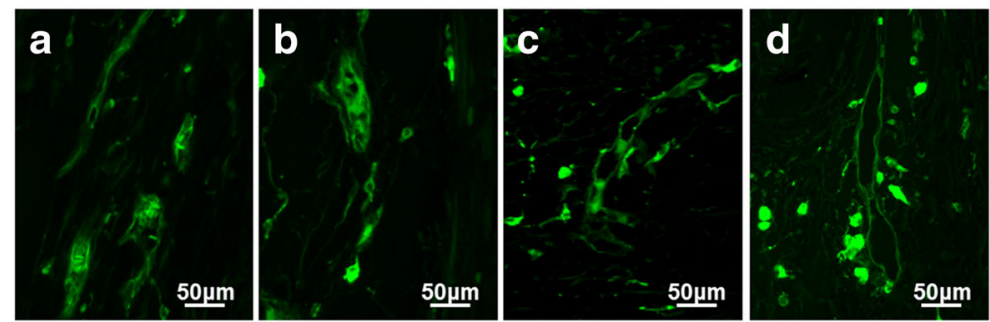

e $(\%)$
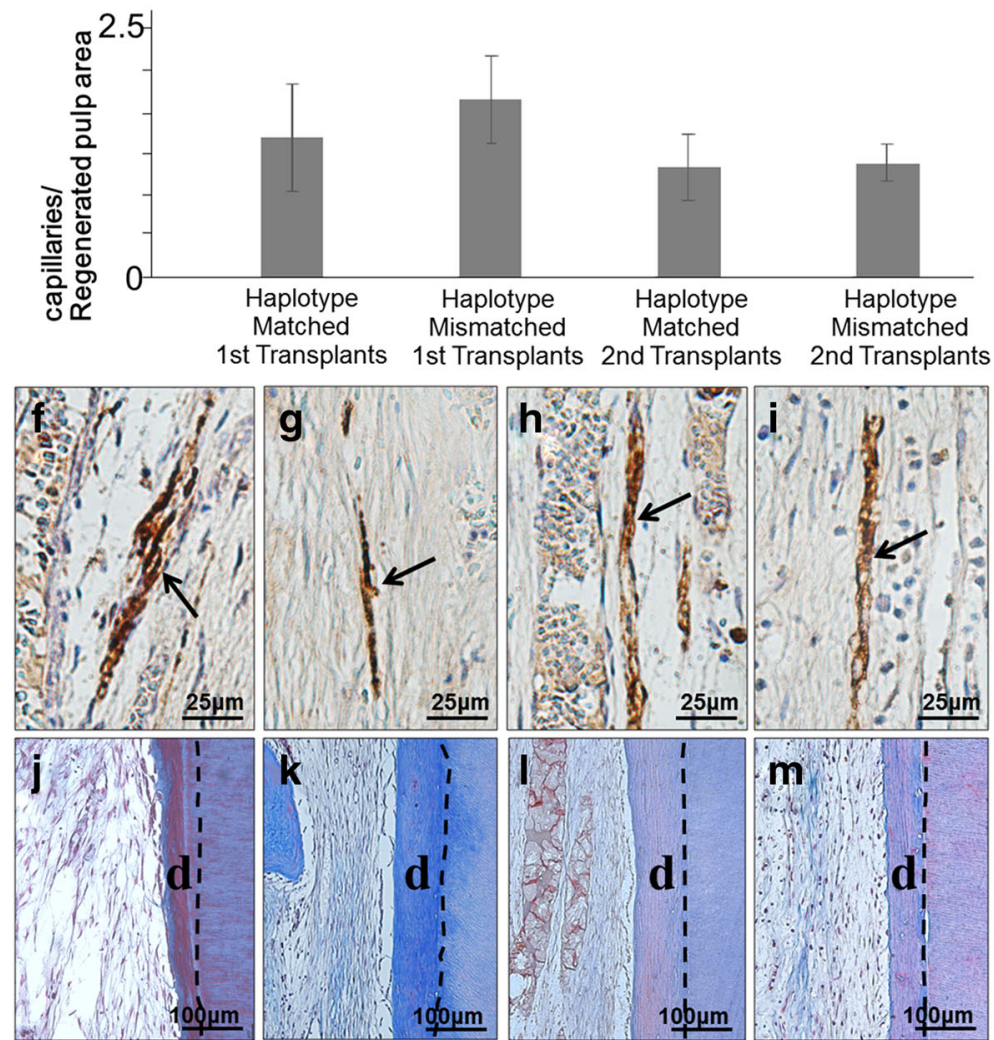

n

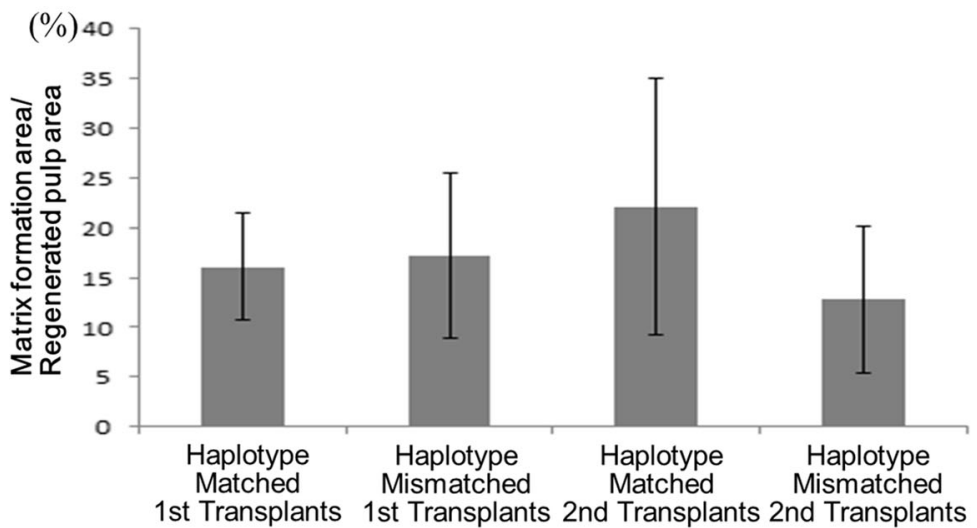

Fig. 3 (See legend on next page.) 
(See figure on previous page.)

Fig. 3 Histochemical analyses of regenerated pulp tissue. Immunostaining with (a-d) BS-1 lectin, (f-i) PGP 9.5 (arrows indicate neurite extension), and (j-m) Masson trichrome staining (hatched lines indicate newly formed osteo/tubular dentin (d)). $\mathbf{a}, \mathbf{b}, \mathbf{f}, \mathbf{g}, \mathbf{j}, \mathbf{k}$ First transplantation. $\mathbf{c}, \mathbf{d}, \mathbf{h}, \mathbf{i}$, I, $\mathbf{m}$ Second transplantation. $\mathbf{a}, \mathbf{c}, \mathbf{f}, \mathbf{h}, \mathbf{j}, \mathbf{I}$ DLA matched transplant. $\mathbf{b}, \mathbf{d}, \mathbf{g}, \mathbf{i}, \mathbf{k}, \mathbf{m}$ DLA mismatched transplant. e Ratio of positively stained area by BS-1 lectin in a frame $310 \mu \mathrm{m} \times 240 \mu \mathrm{m}$ in size. Data are mean \pm standard deviation $(n=4)$. Tukey's multiple comparison test method. $\mathbf{n}$ Ratio of Masson trichrome positively stained area to pulp regenerated area. Data are mean \pm standard deviation $(n=3)$. Tukey's multiple comparison test method

including prostaglandin E synthase (PTGES), COX-2, IL6 , TGF- $\beta$, and IDO1 were similarly expressed in canine MDPSCs compared to canine mobilized adipose-derived MSCs. Fas ligand (FasL) associated with the immunoregulatory properties of DPSCs in the context of inducing T-cell apoptosis [56] was also expressed in MDPSCs (data not shown). The present results are consistent with the previous studies in human MSCs [57-59], demonstrating low immunogenicity of MDPSCs and potential to induce immune tolerance in the hosts.

Furthermore, MSCs can inhibit the immune response not only by suppressing $\mathrm{T}$ cells and by inducing Tregs but also by converting macrophages into a regulatory phenotype [60]. Polarization of macrophages toward the anti-inflammatory M2 phenotype has been reported after DPSC transplantation in diabetic peripheral nerves [61]. In addition, similar findings were seen by injection of conditioned medium from stem cells of human exfoliated deciduous teeth (SHED) into acute lung injury [62], autoimmune encephalomyelitis [63], and rheumatoid arthritis [64]. Further investigation is necessary to examine the shift in the macrophage phenotype from M1 to M2 in the regenerated pulp and periapical tissue after allogeneic DPSC transplantation.

MSCs express detectable levels of MHC class I and low levels of MHC class II to avoid recognition by a host immune system in allogeneic therapies $[65,66]$. Several animal and clinical studies, however, have demonstrated that MSCs are weakly immunogenic in vivo in the case of transplantation across MHC class I barriers and that MSCs are rejected to induce chronic immune responses [31, 67-69]. Such responses could restrict the effectiveness of repeated transplantation of allogeneic MSCs [69]. Syngeneic and minor mismatched transplantation of synovial MSCs demonstrated more optimal meniscus regeneration compared with major mismatched transplantation in a meniscectomized model [70]. On the other hand, the correlation between the number of donorhost MHC mismatches and the efficacy of treatment was not detected in local injection in osteoarthritis and degenerative disc disease [71]. Furthermore, osteogenically differentiated MSCs are immunomodulatory and lack immunogenicity, demonstrating potential use in bone repair. However, maintenance of these properties in vivo is still open to question since immunogenic markers are upregulated after transplantation of the differentiated MSCs [72]. In the present study there was no correlation between the number of donor-host mismatches and efficacy, demonstrating the lack of immune response. This may be due to reduced host immune responses by the transplanted MDPSCs and effective confinement of these cells into the root canal of the tooth. Another possibility is that the transplanted MDPSCs are not differentiated into any host cells in the regenerated pulp tissue. Our previous study demonstrated that injected DiI-labeled autologous MDPSCs did not differentiate into host cells and induced pulp regeneration by secreting trophic factors to elicit migration and proliferation and inhibit apoptosis of endogenous MSCs [8]. We further demonstrated that transplanted porcine pulp MSCs were not directly incorporated into endothelial cells, neuronal cells, or host pulp cells in mouse ectopic tooth transplantation models [6].

Although MSCs are known to be immunoprivileged, repeated transplantation of mismatched MSCs has been reported to lead to alloimmunization and subsequent refractoriness in mice $[67,73]$. Multiple intravenous injections of allogeneic MSCs are well tolerated in healthy horses, indicating no clinical signs of organ toxicity and systemic inflammatory response. A mild alloantigeninduced cytotoxic response, however, is suggested by an increased numbers of circulating $\mathrm{CD} 8^{+} \mathrm{T}$ cells [32]. Dual injection of allogeneic MSCs into joint and articular cartilage induces an adverse clinical response, suggesting immune recognition of allogeneic MSCs after the second infection [74, 75]. Allogeneic MSCs are weakly immunogenic when transplanted across MHC boundaries in rhesus monkeys, indicating negative impact by dual transplantation [76], while repeated intravenous injection of human umbilical cord bloodderived MSCs has low immunogenicity and no adverse events detected in mice [34] and humans [77]. Furthermore, there are no toxicological abnormalities and no obvious pathological changes although $\mathrm{CD}^{+}$and IL-6 levels are significantly increased after repeated intravenous injection of monkey umbilical cord MSCs [78]. In the present study, there were no toxicological abnormalities and no significant difference in tissue volume of regenerated dental pulp and inflammatory cell infiltration between the first and second transplants for both 
DLA matched and mismatched MDPSCs. This result demonstrates that MDPSCs are immunologically safe for use in allogeneic applications.

\section{Conclusion}

In this preclinical study, the safety of allogeneic mismatched MDPSC transplantation in pulpectomized teeth was demonstrated. Regenerated pulp tissues including neovascularization and neuronal extension were similar in the DLA mismatched transplants compared to the DLA matched transplants even after dual transplantation of MDPSCs, suggesting efficacy for total pulp regeneration.

\section{Additional file}

Additional file 1: Figure S1. Histochemical analyses of normal pulp tissue. Immunostaining with (A) BS-1 lectin and (B) PGP 9.5. Neurite extension (arrow). (PDF $155 \mathrm{~kb}$ )

\section{Abbreviations}

G-CSF: Granulocyte colony-stimulating factor; MDPSC: Mobilized dental pulp stem cell

\section{Acknowledgements}

The authors thank Mr Takahiro Nakamura from Shin Nippon Biomedical Laboratories Ltd for technical assistance of allogeneic matched and mismatched transplantation.

\section{Funding}

This work was supported by the Budget for Promoting Science and Technology in Japan, directly following the policy of the Council for Science and Technology Policy (CSTP) chaired by the Prime Minister (to MN).

\section{Availability of data and materials}

Please contact author for data requests.

\section{Authors' contributions}

$\mathrm{Kl}$ contributed to provision of study materials, collection and/or assembly of data, data analysis, and manuscript writing. SU contributed to collection of data and data analysis and interpretation. SK contributed to collection of data and data analysis and interpretation. MN contributed to conception and design, financial support, collection and/or assembly of data, data analysis and interpretation, manuscript writing, and final approval of the manuscript. All authors read and approved the final manuscript.

\section{Ethics approval}

This study was approved by the Animal Care and Use Committee of the National Center for Geriatrics and Gerontology (NCGG) (animal 25-24: national guideline) and Shin Nippon Biomedical Laboratories, Ltd (IACUC 860-013, 015: international guideline). All experiments were conducted using the strict guidelines of DNA Safety Programs.

\section{Competing interests}

The authors declare that they have no competing interests.

\section{Publisher's Note}

Springer Nature remains neutral with regard to jurisdictional claims in published maps and institutional affiliations.

\section{Author details}

'Department of Stem Cell Biology and Regenerative Medicine, National Center for Geriatrics and Gerontology, Research Institute, 7-430 Morioka, Obu Aichi 474-8511, Japan. ${ }^{2}$ Drug Safety Research Laboratories, Shin Nippon Biomedical Laboratories Ltd, Kagoshima, Japan. ${ }^{3}$ Preclinical Research Support Division, Shin Nippon Biomedical Laboratories Ltd, Kainan, Japan.
Received: 22 January 2018 Revised: 23 March 2018

Accepted: 26 March 2018 Published online: 27 April 2018

\section{References}

1. Nakashima M, Akamine A. The application of tissue engineering to regeneration of pulp and dentin in endodontic. J Endod. 2005:31:711-8.

2. Tziafas D. The future role of a molecular approach to pulp-dentinal regeneration. Caries Res. 2004;38:314-20.

3. Murray PE, Garcia-Godoy F, Hargreaves KM. Regenerative endodontics: a review of current status and a call for action. J Endod. 2007;33:377-90

4. Huang GT. Pulp and dentin tissue engineering and regeneration: current progress. Reg Med. 2009;4:697-707.

5. Iohara K, Imabayashi K, Ishizaka R, Watanabe A, Nabekura J, Ito M, et al. Complete pulp regeneration after pulpectomy by transplantation of CD105 + stem cells with stromal cell-derived factor-1. Tissue Eng Part A. 2011:17: 1911-20.

6. Ishizaka R, lohara K, Murakami M, Fukuta O, Nakashima M. Regeneration of dental pulp following pulpectomy by fractionated stem/progenitor cells from bone marrow and adipose tissue. Biomaterials. 2012;33:2109-18.

7. Chen YJ, Zhao YH, Zhao YJ, Liu NX, Lv X, Li Q, Chen FM, Zhang M. Potentia dental pulp revascularization and odonto-/osteogenic capacity of a novel transplant combined with dental pulp stem cells and platelet-rich fibrin. Cell Tissue Res. 2015;361:439-55.

8. Iohara K, Murakami M, Takeuchi N, Osako Y, Ito M, Ishizaka R, et al. A novel combinatorial therapy with pulp stem cells and granulocyte colonystimulating factor for total pulp regeneration. Stem Cells Transl Med. 2013;2: 521-33.

9. Nakashima M, lohara K, Murakami M, Nakamura H, Sato Y, Ariji Y, et al. Pulp regeneration by transplantation of dental pulp stem cells in pulpitis: a pilot clinical study. Stem Cell Res Ther. 2017;8:61.

10. Zhang J, Huang X, Wang H, Liu X, Zhang T, Wang Y, et al. The challenges and promises of allogeneic mesenchymal stem cells for use as a cell-based therapy. Stem Cell Res Ther. 2015:6:234

11. Murakami M, Hayashi $Y$, lohara K, Osako Y, Hirose $Y$, Nakashima M. Trophic effects and regenerative potential of mobilized mesenchymal stem cells from bone marrow and adipose tissue as alternative cell sources for pulp/ dentin regeneration. Cell Transplant. 2015:24:175375.

12. Collart-Dutilleul PY, Chaubron F, De Vos J, Cuisinier FJ. Allogenic banking of dental pulp stem cells for innovative therapeutics. World J Stem Cells. 2015; 7:1010-21.

13. Pittenger MF, Mackay AM, Beck SC, Jaiswal RK, Douglas R, Mosca JD, et al. Multilineage potential of adult human mesenchymal stem cells. Science. 1999;284:143-7

14. Le Blanc K, Tammik C, Rosendahl K, Zetterberg E, Ringdén O. HLA expression and immunologic properties of differentiated and undifferentiated mesenchymal stem cells. Exp Hematol. 2003:31:890-6.

15. Jones BJ, McTaggart SJ. Immunosuppression by mesenchymal stromal cells: from culture to clinic. Exp Hematol. 2008;36:733-41.

16. Ankrum JA, Ong JF, Karp JM. Mesenchymal stem cells: immune evasive, not immune privileged. Nat Biotechnol. 2014;32:252-60.

17. Glenn JD, Whartenby KA. Mesenchymal stem cells: emerging mechanisms of immunomodulation and therapy. World J Stem Cells. 2014:6:526-39.

18. Haddad R, Saldanha-Araujo F. Mechanisms of T-cell immunosuppression by mesenchymal stromal cells: what do we know so far? Biomed Res Int. 2014; 2014:216806.

19. Kyurkchiev D, Bochev I, Ivanova-Todorova E, Mourdjeva M, Oreshkova T, Belemezova K, et al. Secretion of immunoregulatory cytokines by mesenchymal stem cells. World J Stem Cells. 2014;6:552-70.

20. Kim N, Cho SG. New strategies for overcoming limitations of mesenchymal stem cell-based immune modulation. Int J Stem Cells. 2015;8:54-68.

21. Maccario R, Podestà M, Moretta A, Cometa A, Comoli P, Montagna D, et al. Interaction of human mesenchymal stem cells with cells involved in alloantigen-specific immune response favors the differentiation of CD4+ Tcell subsets expressing a regulatory/suppressive phenotype. Haematologica. 2005;90:516-25.

22. Di lanni M, Del Papa B, De loanni M, Moretti L, Bonifacio E, Cecchini D, et al Mesenchymal cells recruit and regulate T regulatory cells. Exp Hematol. 2008:36:309-18.

23. Di Trapani M, Bassi G, Ricciardi M, Fontana E, Bifari F, Pacelli L, et al. Comparative study of immune regulatory properties of stem cells derived from different tissues. Stem Cells Dev. 2013;22:2990-3002. 
24. Imanishi Y, Saito A, Komoda H, Kitagawa-Sakakida S, Miyagawa S, Kondoh H, et al. Allogenic mesenchymal stem cell transplantation has a therapeutic effect in acute myocardial infarction in rats. J Mol Cell Cardiol. 2008;44:662-71.

25. Kim JW, Ha KY, Molon JN, Kim YH. Bone marrow-derived mesenchymal stem cell transplantation for chronic spinal cord injury in rats: comparative study between intralesional and intravenous transplantation. Spine (Phila Pa 1976). 2013;38:E1065-74

26. Gutiérrez-Fernández $M$, Rodríguez-Frutos B, Ramos-Cejudo J, Teresa VallejoCremades M, Fuentes B, Cerdán S, et al. Effects of intravenous administration of allogenic bone marrow- and adipose tissue-derived mesenchymal stem cells on functional recovery and brain repair markers in experimental ischemic stroke. Stem Cell Res Ther. 2013:4:11.

27. Huang $S, X u L$, Sun $Y$, Zhang Y, Li G. The fate of systemically administrated allogeneic mesenchymal stem cells in mouse femoral fracture healing. Stem Cell Res Ther. 2015;6:206.

28. Yang X, Zhu TY, Wen LC, Cao YP, Liu C, Cui YP, et al. Intraarticular injection of allogenic mesenchymal stem cells has a protective role for the osteoarthritis. Chin Med J (Engl). 2015;128:2516-23.

29. Broeckx S, Borena BM, Zimmerman M, Mariën T, Seys B, Suls M, et al. Intravenous application of allogenic peripheral blood-derived mesenchymal stem cells: a safety assessment in 291 equine recipients. Curr Stem Cell Res Ther. 2014;9:452-7

30. Isakova IA, Dufour J, Lanclos C, Bruhn J, Phinney DG. Cell-dose-dependent increases in circulating levels of immune effector cells in rhesus macaques following intracranial injection of allogeneic MSCs. Exp Hematol. 2010;38:957-67.

31. Huang XP, Sun Z, Miyagi Y, McDonald Kinkaid H, Zhang L, Weisel RD, et al. Differentiation of allogeneic mesenchymal stem cells induces immunogenicity and limits their long-term benefits for myocardial repair. Circulation. 2010;122:2419-29.

32. Kol A, Wood JA, Carrade Holt DD, Gillette JA, Bohannon-Worsley LK, Puchalski SM, et al. Multiple intravenous injections of allogeneic equine mesenchymal stem cells do not induce a systemic inflammatory response but do alter lymphocyte subsets in healthy horses. Stem Cell Res Ther. 2015;6:73.

33. Poh KK, Sperry E, Young RG, Freyman T, Barringhaus KG, Thompson CA. Repeated direct endomyocardial transplantation of allogeneic mesenchymal stem cells: safety of a high dose, "off-the-shelf", cellular cardiomyoplasty strategy. Int J Cardiol. 2007;117:360-4.

34. Lee $M$, Jeong SY, Ha J, Kim M, Jin HJ, Kwon SJ, Chang JW, Choi SJ, Oh W, Yang YS, Kim JS, Jeon HB. Low immunogenicity of allogeneic human umbilical cord blood-derived mesenchymal stem cells in vitro and in vivo. Biochem Biophys Res Commun. 2014;446:983-9.

35. Richardson JD, Psaltis PJ, Frost L, Paton S, Carbone A, Bertaso AG, et al. Incremental benefits of repeated mesenchymal stromal cell administration compared with solitary intervention after myocardial infarction. Cytotherapy. 2014;16:460-70.

36. Claudio M, Jonathan KP, Su YK, Ariberto F, Robin AW. Clonal origin and evolution of a transmissible cancer. Cell. 2006;126:477-87.

37. Kennedy LJ, Barnes A, Short A, Brown JJ, Lester S, Seddon J, et al. Canine DLA diversity: 1. New alleles and haplotypes. Tissue Antigens. 2007;69(Suppl 1):272-88. Erratum in: Tissue Antigens 2008;72:88

38. Murakami M, Horibe H, lohara K, Hayashi Y, Osako Y, Takei Y, et al. The use of granulocyte-colony stimulating factor induced mobilization for isolation of dental pulp stem cells with high regenerative potential. Biomaterials. 2013;34:9036-47. Erratum in: Biomaterials 2016;89:166-167

39. Owen R. Odontography; or a Treatise on the Comparative Anatomy of the Teeth; their Physiological Relations, Mode of Development and Microscopic Structure in the Vertebrate Animals. London: Hippolyte Bailliere; 1845.

40. Felsburg PJ. Overview of immune system development in the dog: comparison with humans. Hum Exp Toxicol. 2002;21:487-92.

41. Parker HG, Shearin AL, Ostrander EA. Man's best friend becomes biology's best in show: genome analyses in the domestic dog. Annu Rev Genet. 2010;44:309-36.

42. Volk SW, Theoret C. Translating stem cell therapies: the role of companion animals in regenerative medicine. Wound Repair Regen. 2013;21:382-94.

43. Venkataraman GM, Kennedy LJ, Little ME, Graves SS, Harkey MA, Torok-Storb BJ, et al. Thirteen novel canine dog leukocyte antigen-88 alleles identified by sequence-based typing. HLA. 2017;90:165-70.

44. Kennedy LJ, Altet L, Angles JM, Barnes A, Carter SD, Francino O, et al. Nomenclature for factors of the dog major histocompatibility system (DLA), 1998. First report of the ISAG DLA Nomenclature Committee. International Society for Animals Genetics. Tissue Antigens. 1999;54:312-21.
45. Kennedy $L$, Angles JM, Barnes A, Carter SD, Francino O, Gerlach JA, et al. Nomenclature for factors of the dog major histocompatibility system (DLA), 2000: second report of the ISAG DLA Nomenclature Committee. Anim Genet. 2001;32:193-9.

46. Wagner $J$, Burnett RC, Storb R. Organization of the canine major histocompatibility complex: current perspectives. J Hered. 1999;90:35-8.

47. Yuhki N, Beck T, Stephens R, Neelam B, O'Brien SJ. Comparative genomic structure of human, dog, and cat MHC: HLA, DLA, and FLA. J Hered. 2007; 98:390-9.

48. Gornostaeva A, Andreeva E, Buravkova L. Factors governing the immunosuppressive effects of multipotent mesenchymal stromal cells in vitro. Cytotechnology. 2016;68:565-77.

49. Tang R, Ding G. Swine dental pulp stem cells inhibit T-cell proliferation. Transplant Proc. 2011;43:3955-9.

50. Wada N, Menicanin D, Shi S, Bartold PM, Gronthos S. Immunomodulatory properties of human periodontal ligament stem cells. J Cell Physiol. 2009; 219:667-76.

51. Tomic S, Djokic J, Vasilijic S, Vucevic D, Todorovic V, Supic G, et al. Immunomodulatory properties of mesenchymal stem cells derived from dental pulp and dental follicle are susceptible to activation by toll-like receptor agonists. Stem Cells Dev. 2011;20:695-708.

52. Trivanović D, Mojsilović S, llić V, Krstić J, Jauković A, Okić-Dordević I, et al. Immunomodulatory capacity of human mesenchymal stem cells isolated from adipose tissue, dental pulp, peripheral blood and umbilical cord Wharton's jelly. Centr. Eur J Immunol. 2013;38:21-9.

53. Ding G, Niu J, Liu Y. Dental pulp stem cells suppress the proliferation of lymphocytes via transforming growth factor- $\beta 1$. Hum Cell. 2015;28:81-90.

54. Özdemir AT, Özgül Özdemir RB, Kırmaz C, Sarıboyacı AE, Ünal Halbutoğllar ZS, Özel C, et al. The paracrine immunomodulatory interactions between the human dental pulp derived mesenchymal stem cells and CD4 T cell subsets. Cell Immunol. 2016;310:108-15.

55. Kwack KH, Lee JM, Park SH, Lee HW. Human dental pulp stem cells suppress alloantigen-induced immunity by stimulating $T$ cells to release transforming growth factor beta. J Endod. 2017;43:100-8.

56. Zhao Y, Wang L, Jin Y, Shi SJ. Fas ligand regulates the immunomodulatory properties of dental pulp stem cells. Dent Res. 2012;91:948-54.

57. Klyushnenkova E, Mosca JD, Zernetkina V, Majumdar MK, Beggs KJ, Simonetti DW, et al. T cell responses to allogeneic human mesenchymal stem cells: immunogenicity, tolerance, and suppression. J Biomed Sci. 2005;12:47-57.

58. Herrero C, Pérez-Simón JA. Immunomodulatory effect of mesenchymal stem cells. Braz J Med Biol Res. 2010;43:425-30.

59. Liu S, Yuan M, Hou K, Zhang L, Zheng X, Zhao B, et al. Immune characterization of mesenchymal stem cells in human umbilical cord Wharton's jelly and derived cartilage cells. Cell Immunol. 2012;278:35-44.

60. Prockop DJ. Concise review: two negative feedback loops place mesenchymal stem/stromal cells at the center of early regulators of inflammation. Stem Cells. 2013;31:2042-6.

61. Omi M, Hata M, Nakamura N, Miyabe M, Kobayashi Y, Kamiya H, et al. Transplantation of dental pulp stem cells suppressed inflammation in sciatic nerves by promoting macrophage polarization towards anti-inflammation phenotypes and ameliorated diabetic polyneuropathy. J Diabetes Investig 2016;7:485-96

62. Wakayama H, Hashimoto N, Matsushita Y, Matsubara K, Yamamoto N, Hasegawa $Y$, et al. Factors secreted from dental pulp stem cells show multifaceted benefits for treating acute lung injury in mice. Cytotherapy. 2015;17:1119-29.

63. Shimojima C, Takeuchi H, Jin S, Parajuli B, Hattori H, Suzumura A, et al. Conditioned medium from the stem cells of human exfoliated deciduous teeth ameliorates experimental autoimmune encephalomyelitis. J Immunol. 2016;196:4164-71

64. Ishikawa J, Takahashi N, Matsumoto T, Yoshioka Y, Yamamoto N, Nishikawa $M$, et al. Factors secreted from dental pulp stem cells show multifaceted benefits for treating experimental rheumatoid arthritis. Bone. 2016;83:210-9.

65. Dominici M, Le Blanc K, Mueller I, Slaper-Cortenbach I, Marini F, Krause D, et al. Minimal criteria for defining multipotent mesenchymal stromal cells. The International Society for Cellular Therapy position statement. Cytotherapy. 2006:8:315-7.

66. Siegel G, Schäfer R, Dazzi F. The immunosuppressive properties of mesenchymal stem cells. Transplantation. 2009:87(9 Suppl):S45-9.

67. Eliopoulos N, Stagg J, Lejeune L, Pommey S, Galipeau J. Allogeneic marrow stromal cells are immune rejected by MHC class I- and class II-mismatched recipient mice. Blood. 2005;106:4057-65. 
68. Hare JM, Fishman JE, Gerstenblith G, DiFede Velazquez DL, Zambrano JP, Suncion VY, et al. Comparison of allogeneic vs autologous bone marrowderived mesenchymal stem cells delivered by transendocardial injection in patients with ischemic cardiomyopathy: the POSEIDON randomized trial. JAMA. 2012;308:2369-79.

69. Pezzanite LM, Fortier LA, Antczak DF, Cassano JM, Brosnahan MM, Miller D, et al. Equine allogeneic bone marrow-derived mesenchymal stromal cells elicit antibody responses in vivo. Stem Cell Res Ther. 2015;6:54.

70. Okuno M, Muneta T, Koga H, Ozeki N, Nakagawa Y, Tsuji K, et al. Meniscus regeneration by syngeneic, minor mismatched, and major mismatched transplantation of synovial mesenchymal stem cells in a rat model. J Orthop Res. 2014;32:928-36.

71. García-Sancho J, Sánchez A, Vega A, Noriega DC, Nocito M. Influence of HLA matching on the efficacy of allogeneic mesenchymal stromal cell therapies for osteoarthritis and degenerative disc disease. Transplant Direct. 2017:3:e205.

72. Zhang X, Tang T, Shi Q, Fernandes JC, Dai K. The immunologic properties of undifferentiated and osteogenic differentiated mouse mesenchymal stem cells and its potential application in bone regeneration. Immunobiology. 2009;214:179-86.

73. Nauta AJ, Westerhuis G, Kruisselbrink AB, Lurvink EG, Willemze R, Fibbe WE, Donor-derived mesenchymal stem cells are immunogenic in an allogeneic host and stimulate donor graft rejection in a nonmyeloablative setting. Blood. 2006;108:2114-20

74. Ardanaz N, Vázquez FJ, Romero A, Remacha AR, Barrachina L, Sanz A, et al. Inflammatory response to the administration of mesenchymal stem cells in an equine experimental model: effect of autologous, and single and repeat doses of pooled allogeneic cells in healthy joints. BMC Vet Res. 2016;12:65.

75. Joswig AJ, Mitchell A, Cummings KJ, Levine GJ, Gregory CA, Smith R 3rd, et al. Repeated intra-articular injection of allogeneic mesenchymal stem cells causes an adverse response compared to autologous cells in the equine model. Stem Cell Res Ther. 2017;8:42.

76. Isakova IA, Lanclos C, Bruhn J, Kuroda MJ, Baker KC, Krishnappa V, et al. Allo-reactivity of mesenchymal stem cells in rhesus macaques is dose and haplotype dependent and limits durable cell engraftment in vivo. PLoS One. 2014;9:e87238.

77. Wang X, Yin X, Sun W, Bai J, Shen Y, Ao Q, et al. Intravenous infusion umbilical cord-derived mesenchymal stem cell in primary immune thrombocytopenia: a two-year follow-up. Exp Ther Med. 2017:13:2255-8.

78. He J, Ruan GP, Yao X, Liu JF, Zhu XQ, Zhao J, et al. Chronic toxicity test in cynomolgus monkeys for 98 days with repeated intravenous infusion of cynomolgus umbilical cord mesenchymal stem cells. Cell Physiol Biochem. 2017:43:891-904.

\section{Submit your next manuscript to BioMed Central and we will help you at every step:}

- We accept pre-submission inquiries

- Our selector tool helps you to find the most relevant journal

- We provide round the clock customer support

- Convenient online submission

- Thorough peer review

- Inclusion in PubMed and all major indexing services

- Maximum visibility for your research

Submit your manuscript at www.biomedcentral.com/submit

C Biomed Central 